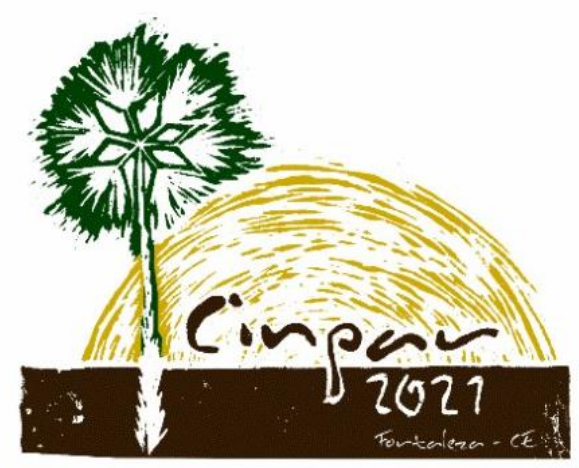

XVII Congresso Internacional sobre Patologia e Reabilitação das Construções

XVII Congreso Internacional sobre Patología y Rehabilitación de las Construcciones

XVII International Conference on Pathology and Constructions Rehabilitation

FORTALEZA (Brasil), 3 a 5 de junho de 2021 https://doi.org/10.4322/CINPAR.2021.032

\title{
ESTUDO DA DOSAGEM DE CONCRETO COM ADIÇÃO DE FIBRA DE COCO
}

\section{STUDY OF CONCRETE DOSING WITH ADDITION OF COCONUT FIBER}

\author{
Rafaela ZARA ${ }^{1}$, Enio BOLOGNINI ${ }^{2}$, José ARMANI ${ }^{3}$, Roseane VILELA ${ }^{4}$ \\ R. P. Zara (1), E. J. Bolognini (2), J. A. A. Paschoal (3), R. L. Vilela (4) \\ ${ }^{1}$ Graduada de Engenharia Civil - UNIP/JK/S.J.R.P - email: rafaela_panula@hotmail.com \\ ${ }^{2}$ Professor Mestre em Engenharia Civil - UNIP/JK/S.J.R.P - email: enio.bolognini@docente.unip.br \\ ${ }^{3}$ Professor Doutor em Engenharia Civil - UNIP/JK/S.J.R.P - email: jose.paschoal@ docente.unip.br \\ ${ }^{4}$ Professora Mestre em Engenharia Civil - UNIP/JK/S.J.R.P - email: roseane.I.vilela@gmail.com
}

\begin{abstract}
Resumo: Este estudo trata-se da exploração das propriedades do concreto, focando necessariamente em seu comportamento quando adicionado a fibra do coco, almejando buscar a proporção exata de cada elemento compositor do concreto para melhor desempenho em fluidez e resistência destinada a futura comercialização. Visto que a fibra do coco apresenta teores de celulose, que por sua vez agrega firmeza ao concreto, poderá, por meio deste estudo, verificar sua reação quanto elasticidade e resistência a compressão entre outros benéficos levando em consideração a decomposição da mesma ao longo do tempo. Serão realizados ensaios de granulometria, densidade, absorção e abatimento, cura e rompimento para conclusão do diagrama de dosagem. Esta pesquisa promoverá uma escolha produtiva e duradoura na quantidade de fibra e agregados necessários na dosagem do concreto para uma economia associada à reutilização de matérias orgânicas, garantindo eficácia na construção civil.
\end{abstract}

Palavras-chave: coco, concreto, construção civil.

Abstract: This study deals with the exploration of concrete properties, necessarily focusing on their behavior when added to coconut fiber, aiming to seek the exact proportion of each concrete composing element for better performance in fluidity and resistance for future commercialization. Since the coconut fiber has cellulose contents, which in turn adds firmness to the concrete, you can, through this study, check its reaction regarding elasticity and resistance to compression, among other benefits taking into account its decomposition over time. Granulometry, density, absorption and abatement, curing and breaking tests will be carried out to complete the dosage diagram. This research will promote a productive and lasting choice in the amount of fiber and aggregates needed in the concrete dosage for an economy associated with the reuse of organic materials, ensuring efficiency in civil construction.

Keywords: coconut, concrete, civil construction.

\section{Introdução}

Neste estudo da confecção de concreto foi realizado e demonstrado o comportamento do concreto convencional (CC), com relação ao concreto com adição de fibra do coco (CAFC), sendo uma alternativa para solucionar problemas e recuperar estruturas degradadas, em relação a flexibilidade, elasticidade e resistência à compressão.

Os concretos devem conter na mistura os agregados graúdos porosos para alojar partículas finas, assim o desempenho é excepcional. A chave está na microestrutura do material, sendo que os materiais mais porosos contêm menor absorção de água, ao contrário dos agregados miúdos que contém maior absorção de água por serem consideradas partículas finas, onde misturada com à argamassa o contato com as partículas de 
cimento pode resultar em estrutura mais densas, o que beneficiaria a difusão dos grãos finos do cimento com as camadas mais externas dos agregados graúdos. (YOUNIS \& PILAKOUTAS, 2013).

Bolognini et. al. (2015), discorrem sobre a necessidade de que a dosagem esteja de acordo com a seleção dos materiais caracterizados definidos pela massa específica $\left(\mathrm{g} / \mathrm{cm}^{3}\right.$ ) deparando com fluidez do concreto (sem segregação e exsudação), que quando submetidos a mistura adequada, irão obter melhor resistência à compressão (MPa).

Estudando as matrizes cimentícias, nota-se muitas vezes a inserção de aglomerantes minerais, tudo para encontrar o teor ideal de água, cimento e agregados, que possibilite ao concreto excelente trabalhabilidade e fluidez sem segregar, deixando-o mais resistente conforme as normas exigidas e reduzindo seu custo financeiro de investimento. Para Bolognini et. Al. (2015), a confecção do concreto depende do abatimento realizado durante os ensaios laboratoriais, a fim de apresentar homogenidade com relação a pasta de concreto.

Em determinadas análises deve-se utilizar entre três tipos de aglomerantes hidráulicos de cimento Portland simples (PC-CEM I 52.5N; 70/30 PC/FA e; 50/50 PC/GGBS), sendo que o segundo contém cinzas e o terceiro escória de alto-forno triturada. Outro material utilizado, foram britas de granitos com diâmetro de 13,2 mm, juntamente com a areia do granito (agregados graúdos e miúdos). Por fim, as barras continham diâmetros de $20 \mathrm{~mm}$ à $30 \mathrm{~mm}$ e de $12 \mathrm{~mm}$, sendo que as maiores foram para profundidade de cobertura (OTIENO et. al., 2019).

Em meio a este quesito, a inserção de novas matérias-primas à argamassa gera o estudo de adição de fibras vegetais, sendo elas muitas vezes, do aço, vidro, polipropileno, náilon, e como neste estudo, as fibras do coco. Segundo Silva et. al. (2012), a adição de fibras durante a execução pode melhorar as propriedades mecânicas, sendo exemplo o impacto, à resistência a tração e compressão, gerando também, modificação em seu comportamento após fissuração diminuindo os efeitos de uma ruptura brusca da matriz cimentícia. Os materiais utilizados na confeç̧ão de concreto foram ensaiados e obtidos os seguintes dados: granulometria, massa específica e absorção dos agregados e fibras.

Neste sentido, foi aplicado os modelos dos traços: médio, rico e pobre; e igualmente para o traço com adição de fibra. Por fim, estipulou-se para o ensaio de compressão 9, 28 e 91 dias, sendo apresentados os diagramas de dosagem segundo o método de Helene e Terezian (1993). Para isso, utilizou-se os diagramas de dosagem utilizando as leis de Abrams, Lyse e Molinari, para demonstrar concretos flexiveis visando redução de custos nas estruturas que apresentam estruturas com trincas e expansibilidades.

\section{Estudo de Casos}

\subsection{Processo da Confecção de Concreto}

Sendo assim, os principais ensaios realizados foram de caracterização destes materiais, como também, na apresentação de curvas granulometrias conforme a ABNT NBR NM 7211 (2009).

Os ensaios laboratoriais de granulometria dos agregados graúdos e miúdos, e também, da massa especifica e absorção, foram ensaiados e calculados de acordo com a ABNT NBR NM 52 (2009) e ABNT NBR NM 53 (2009). A equação 1 expõe o valor do módulo de finura (MF) dos agregados miúdos:

$$
M_{f}=\frac{\sum \% \text { retida acumulada }}{100}
$$

Onde:

- $M_{f}$ - Módulo de finura de agregado miúdo;

- $\sum \%$ retida acumulada - Soma proporcional da massa retida acumulada;

A equação 2, apresenta o valor de massa específica dos agregados miúdos:

$$
\gamma_{a}=\frac{500}{L-200 m l}
$$

Estudo da Dosagem do Concreto com Adição da Fibra do Coco 
Onde:

- $\gamma_{a}$-Massa específica do agregado miúdo (areia), expressa em $\mathrm{kg} / \mathrm{cm}^{3}$;

- $\quad L$ - Leitura do frasco (volume ocupado pelo conjunto água - agregado miúdo);

A equação 3 é para encontrar a massa específica do cimento e da fibra do coco.

$\gamma_{b}=\frac{M_{s}}{M_{h}-L}$

(Equação 3)

Onde:

- $\gamma_{b}$ - Densidade do agregado graúdo;

- $M_{S}$ - Massa do agregado seco em estufa, após resfriado à temperatura de manipulação, em g;

- $M_{h}$ - Massa do agregado na condição saturada seca, em g;

- $L$ - Leitura na balança quando agregado submerso em recipiente acoplado à mesma.

$$
A=\frac{M_{h}-M_{S}}{M_{S}} \times 100
$$

Onde:

- A - Absorção do agregado, em porcentagem;

- $M_{S}$ - Massa do agregado seco em estufa, à temperatura de manipulação, em g;

- $M_{h}$ - Massa do agregado na condição saturada seca, em g.

Conforme Helene e Terzian (1993), com as quantidades em massa (kg) para confeccionar os concretos, é preciso para os ensaios de dosagem e abatimento, aplicar as equações 5 a 10, sendo possível de tal maneira, obter respectivas dosagens para o teor de argamassa ideal $(\alpha)$.

$$
\begin{aligned}
& \alpha=\frac{1+a}{1+m} \\
& m=a+b \\
& C=\frac{1000-A r}{\left(\frac{1}{\gamma_{c}}+\frac{a}{\gamma_{a}}+\frac{b}{\gamma_{b}}+a / c\right)} \\
& C_{a}=a \times C \\
& C_{b}=b \times C \\
& C_{\text {água }}=a / c \times C
\end{aligned}
$$

Onde:

- $\quad \alpha$-é a porcentagem de argamassa;

- $a$ - é a proporção de areia no traço;

- $m$ - é a proporção de areia mais agregado graúdo no traço;

- $\quad b$ - é a proporção de brita no traço;

- $C$-é o consumo de cimento por metro cúbico de concreto;

- $\gamma_{c}$ - é a massa específica do cimento em gramas por centímetro cúbico;

- $\gamma_{a}$ - é a massa específica da areia em gramas por centímetro cúbico;

- $\gamma_{b}$ - é a massa específica das britas em gramas por centímetro cúbico;

- $C_{a}$-é o consumo de areia em quilos;

- $C_{b}$-é o consumo de britas em quilos;

Estudo da Dosagem do Concreto com Adição da Fibra do Coco 
- $C_{\text {água }}$ - é o consumo de água em litros;

- $a / c$ - é a relação água cimento do concreto.

\section{Materiais e Métodos}

\subsection{Metodologia de Caracterização dos Materiais Naturais e Orgânicos}

Os materiais utilizados neste trabalho para confecção do concreto foram: cimento Portland CP II 40 - F, areia grossa, britas de basalto (B1), fibra do coco e água do abastecimento próprio da Universidade Paulista (UNIP, Campus JK, S.J.R.P./SP). Já para a fibra do coco, também foi realizado ensaio de massa especifica, após a mesma ter sido cortado em pedaços menores, a fim de obter os dados de massa específica e absorção. Os ensaios de granulometria das séries de abertura das peneiras de agregados graúdos e miúdos devem ser de acordo com as normas da ABNT NBR NM 30 (2001) e ABNT NBR NM 7211 (2009), sendo que o primeiro ensaio realizado de granulometria da areia teve como diametro máximo o valor de $2,40 \mathrm{~mm}$ e módulo de finura entre 2,90 a 3,50 mm classificada como areia grossa. Quanto a sua massa específica, variou entre 2,64 $\mathrm{g} / \mathrm{cm}^{3}$ e $2,63 \mathrm{~g} / \mathrm{cm}^{3}$, como demonstrados nas Figuras $1 \mathrm{a}$ e $1 \mathrm{~b}$.

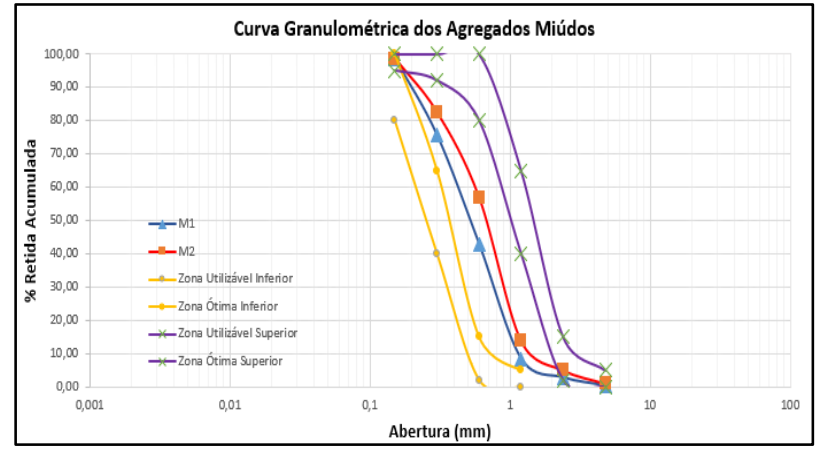

(a)

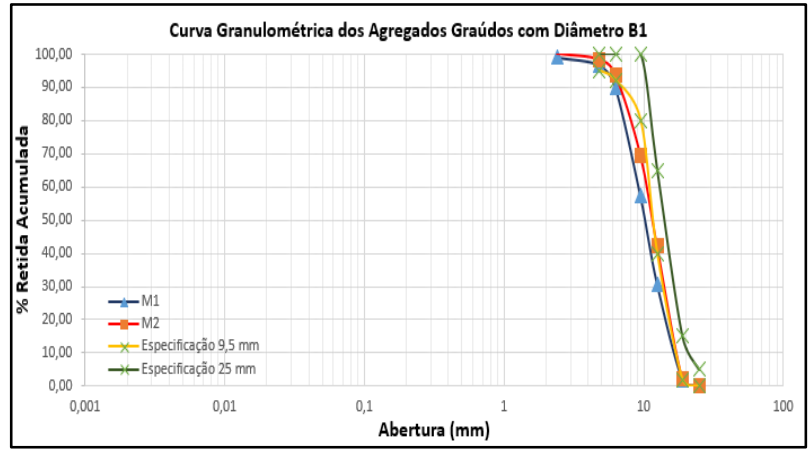

(b)

Figura 1: Apresentação das curvas granulométricas dos agregados miúdos (a) e agregados graúdos (b)

Já a brita de basalto, obteve sua granulometria válida pela a ABNT NBR NM 248:2003, com massa específica variante entre $2,78 \mathrm{~kg} / \mathrm{cm}^{3}$ à $2,80 \mathrm{~kg} / \mathrm{cm}^{3}$ em suas amostra. A proporção de absorção de água dos graúdos variou entre $0,62 \%$ à $1,36 \%$.

O mesmo ensaio de massa específica também ocorreu com fibra do coco, na qual foram utilizou uma quantidade em massa da fibra picotada em aproximadamente $0.5 \mathrm{~mm}$, que logo após de ter seus poros saturados, foi aferido em provetas contendo uma água e a outra álcool. O resultado encontrado foi de 1,12 $\mathrm{g} / \mathrm{cm}^{3}$ para a quantidade imersa álcool e $1,07 \mathrm{~g} / \mathrm{cm}^{3}$ para água.

\subsection{Metodologia da Confecção de Concreto}

Para os ensaios de dosagem e abatimento, foi necessários as equações de 05 à 10 proprostas por Helene e Terzian (1993) em concordância com ABNT NBR NM 67 (1998), sendo assim, foi possível se obter os cálculos destas dosagens, utilizando as planilhas do Microsoft Excel, para alcançar o teor de argamassa ideal $(\alpha)$.

Afim de comparar as resistências axiais do concreto convencional com adição de fibra do coco, foram realizados três traços sendo eles: 1:3,5 (rico); 1:5,0 (médio) e; 1:6,5 (pobre) para cada tipo de concreto.

Conforme a Tabela 1, é um exemplo das demais dosagens que se pode através das planilhas elaborar e confeccionar concreto, ou seja, utilizando o concreto com adição de fibras do coco(CAFC), no teor de argamassa 49\%. Ressalta-se a necessidade de umedecer a betoneira antes de bater o concreto, a fim de evitar perdas pela absorção de água em volta das paredes internas. 
Durante os ensaios houve o abatimento para analisar a consistência de argamassa com ajuda de uma pá (com concreto ainda dentro da betoneira).

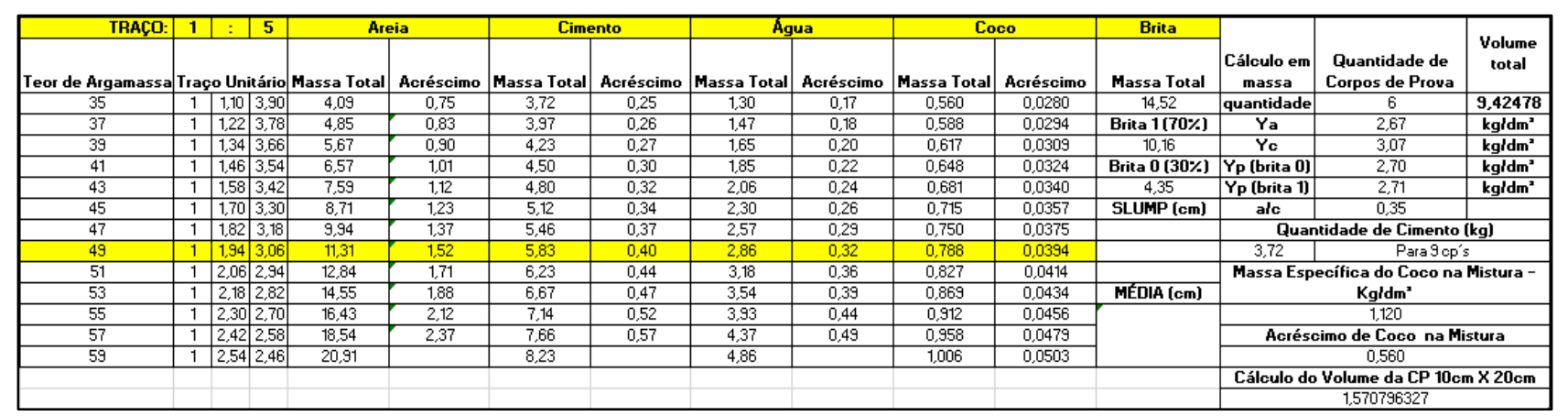

Tabela 1: Exemplo de planilha do traço 1:5,0 referente ao concreto com adição de fibras do coco (CAFC)

Sendo assim, as Tabelas 2 e 3, representam os traços confeccionados de concreto com as respectivas dosagens em 1:3,5; 1:5,0 e; 1:6,5; para concretos convencionais (CC) e concretos com adição de fibras do coco (CAFC).

\begin{tabular}{|c|c|c|c|c|c|c|c|c|c|c|c|}
\hline \multicolumn{2}{|c|}{ CONCRETO CONVECIONAL (CC) } & & \multirow{2}{*}{\multicolumn{2}{|c|}{$\begin{array}{l}\text { CIMENTO: } \\
\text { Unitário }\end{array}$}} & \multicolumn{2}{|c|}{$\mathrm{CP} \| 40-\mathrm{F}$} & BRITA: & BASALTO & \multicolumn{2}{|c|}{ DIMENSÃO: } & B1 \\
\hline \multirow{2}{*}{$\begin{array}{c}\text { Teor de } \\
\text { Argamassa } \\
\text { Ideal }\end{array}$} & \multirow{2}{*}{ Traço Experimental } & Traço Unitário & & & \multicolumn{5}{|c|}{ Traço em Massa (kg) } & \multirow{2}{*}{\multicolumn{2}{|c|}{$\begin{array}{l}\text { Abatimento } \\
\text { (cm) }\end{array}$}} \\
\hline & & c & a & b & c (kg) & a (kg) & B1 (kg) & água (kg) & $a / c$ & & \\
\hline $49 \%$ & $1: 3,5$ & 1,00 & 1,21 & 2,29 & 10,07 & 12,18 & 23,23 & 4,93 & 0,32 & 6,5 & \\
\hline $49 \%$ & $1: 5,0$ & 1,00 & 1,94 & 3,06 & 8,31 & 16,13 & 24,19 & 4,07 & 0,49 & 7,0 & \\
\hline $49 \%$ & $1: 6,5$ & 1,00 & 2,68 & 3,82 & 7,19 & 19,28 & 24,76 & 3,52 & 0,66 & 7,5 & \\
\hline
\end{tabular}

Tabela 2: Traço referencia concreto do convencional (CC)

\begin{tabular}{|c|c|c|c|c|c|c|c|c|c|c|c|c|}
\hline \multicolumn{2}{|c|}{ CAFC } & \multirow{2}{*}{\multicolumn{3}{|c|}{$\begin{array}{l}\text { CIMENTO: } \\
\text { Traço Unitário }\end{array}$}} & \multicolumn{2}{|c|}{$\mathrm{CP} \| 40-\mathrm{F}$} & \multicolumn{2}{|c|}{ BRITA: } & BASALTO & \multicolumn{2}{|c|}{ DIMENSÃO: } & \multirow{3}{*}{$\begin{array}{c}\mathrm{B} 1 \\
\begin{array}{c}\text { Abatimento } \\
(\mathrm{cm})\end{array}\end{array}$} \\
\hline \multirow{2}{*}{$\begin{array}{c}\text { Teor de } \\
\text { Argamassa } \\
\text { Ideal }\end{array}$} & \multirow{2}{*}{$\begin{array}{c}\text { Traço } \\
\text { Experime } \\
\text { ntal }\end{array}$} & & & & \multicolumn{7}{|c|}{ Traço em Massa (kg) } & \\
\hline & & c & a & b & c (kg) & a (kg) & $\begin{array}{c}\text { B1 } \\
\text { (kg) }\end{array}$ & $\begin{array}{l}\text { Coco } \\
(\mathrm{kg})\end{array}$ & $\begin{array}{c}\text { Superplastificante } \\
(\mathrm{kg})\end{array}$ & $\begin{array}{c}\text { água } \\
\text { (kg) }\end{array}$ & $a / c$ & \\
\hline $49 \%$ & $1: 3,5$ & 1,00 & 1,21 & 2,29 & 6,88 & 8,33 & 13,94 & 1,024 & - & 3,37 & 0,44 & 6,00 \\
\hline $49 \%$ & $1: 5,0$ & 1,00 & 1,94 & 3,06 & 5,83 & 11,31 & 14,52 & 0,788 & - & 2,98 & 0,52 & 6,50 \\
\hline $49 \%$ & $1: 6,5$ & 1,00 & 2,68 & 3,82 & 5,16 & 13,83 & 14,85 & 0,552 & - & 2,53 & 0,59 & 8,00 \\
\hline
\end{tabular}

Tabela 3: Traço referencia concreto do com adição da fibra do coco (CAFC)

\subsection{Metodologia de Abatimento e Cura do Concreto}

A partir da tabela 5 e 6, estão representados os resultados por meio de planilhas do Microsoft Excel, sendo que as dosagens de argamassa utilizadas obtiveram maior eficácia ao trabalhar com estas quantidades de massa $(\mathrm{kg})$ dos materiais na betoneira, apresentando assim ótimo desempenho de cura e ensaios mecânicos entre os períodos de 7, 28 e 91 dias.

Para estes ensaios mecânicos, foram rompidos em geral 27 exemplares, sendo de acordo com o teor de argamassa ideal $(\alpha)$ em $49 \%$, para o traço 1:5,0 dos concretos convencionais (CC). Assim, encontramos os valores correspondentes ao ensaio de compressão axial, que são demonstrados na Tabela 4 a média e desvio padrão para o concreto rico 1:3,5 e pobre também 1:6, nos dias 7, 28 e 91.

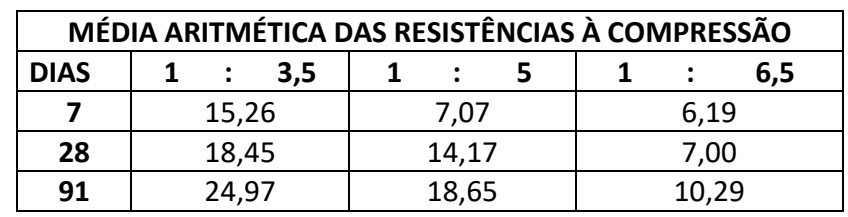

\begin{tabular}{|c|ccc|cc|c|c|c|}
\hline \multicolumn{7}{|c|}{ DESVIO PADRÃO DAS RESISTÊNCIAS À COMPRESSÃO } \\
\hline DIAS & $\mathbf{1}$ & $\mathbf{2}$ & $\mathbf{3 , 5}$ & $\mathbf{1}$ & $\mathbf{:}$ & $\mathbf{5}$ & $\mathbf{1}$ & $\mathbf{6}$ \\
\hline $\mathbf{7}$ & 4,22128732 & 0,661362231 & 0,020548047 \\
\hline $\mathbf{2 8}$ & 1,8861071 & \multicolumn{2}{|c|}{0,371513421} & 0,342928564 \\
\hline $\mathbf{9 1}$ & 1,44928335 & 0,30619529 & 0,518480686 \\
\hline
\end{tabular}

Tabela 4: Desvio padrão e média dos ensaios mecânicos referentes ao concreto convencional (CC)

Os ensaios mecânicos foram rompidos em geral 27 exemplares, onde estão de acordo com o teor de argamassa ideal $(\alpha)$ em $49 \%$, para o traço 1:5,0 dos concretos com adição de fibras do coco (CAFC). 
Na Tabela 5 são demonstrados a média e desvio padrão para o concreto rico 1:3,5 e pobre também 1:6, nos dias 7, 28 e 91.

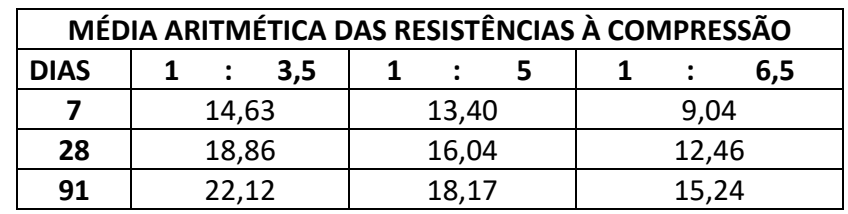

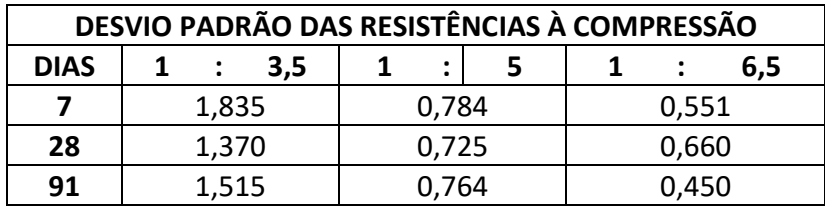

Tabela 5: Desvio padrão e média caracteristica dos ensaios mecânicos referentes ao concreto com adição da fibra do coco (CAFC)

\section{$4 \quad$ Resultados e Discussões}

Ao apresentar os dados obtidos durante cálculos, ensaios laboratoriais e mecânicos, é possível apresentar o aumento significativo da média aritmética de resistência à compressão, ou seja, com o passar dos dias na cura, tanto o concreto convencional (CC), quanto o concreto com adição da fibra do coco (CAFC), demonstraram ótimo desempenho de resistência à compressão.

Nas Figuras 2a e 2b e 3, são apresentados os diagramas de dosagem segundos as leis de Abrams, Lyse e Molinari, para os concretos convencionais (CC), assim demonstrando os resultados nas curvas que ficaram de acordo com esperado entre os períodos de 7, 28 e 91 dias.

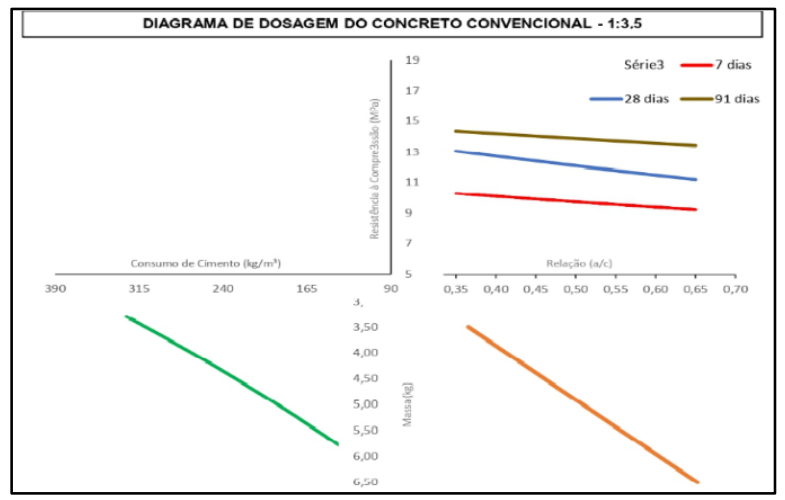

(a)

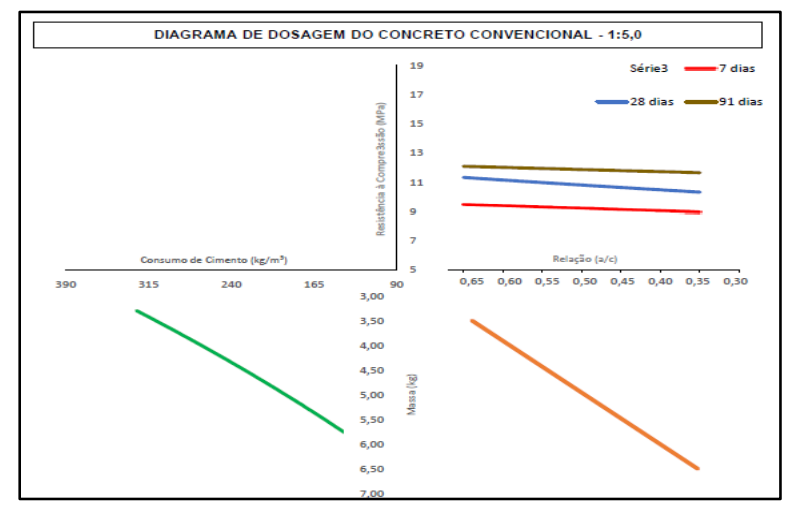

(b)

Figura 2: Apresentação das curvas de Abrams, Lyse e Molinari dos concretos convencionais (CC) segundos os traços: 1:3,5 (a) e 1:5,0 (b)

Está análise condiz ao termo proposto deste estudo, o que torna realmente possível o uso da fibra na mistura da argamassa. Por fim, o traço 1:6,5 apresentou queda expressiva de resistência e possibilidade de melhor utilidade em argamassas de recuperação de estruturas.

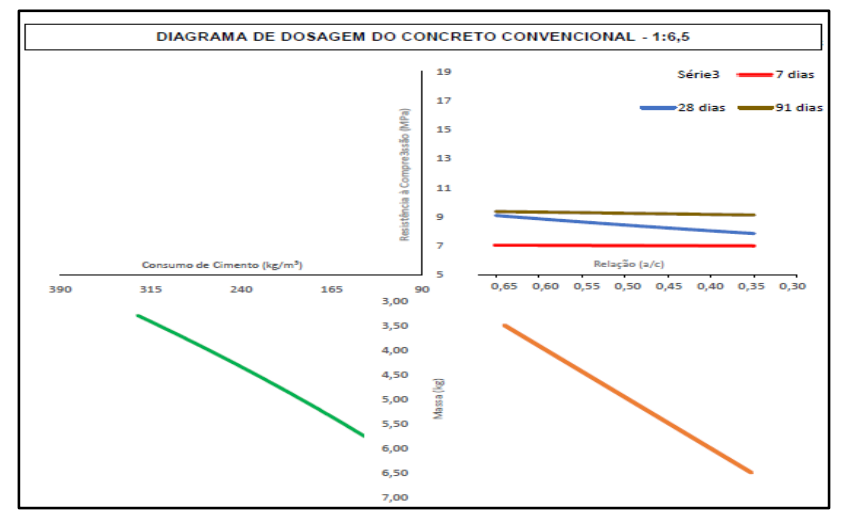

Figura 3: Curvas de Abrams, Lyse e Molinari do concreto convencional (CC) segundo o traço: 1:6,5 (c). 
Nas Figuras 4a, 4b e 4c, são apresentados os diagramas de dosagem dos concretos com adição da fibra do coco (CAFC), onde foi possível detectar em ambos os casos o aumento expressivo na resistência à compressão $(\mathrm{MPa})$. Embora os valores relacionados aos gráficos não foram tão abrangentes, como apresentados no concreto convencional (CC), se pode apresentar um concreto flexível, ou seja, as presentes curvas obtiveram aumento proporcional a relação quanto a idade e consumo de cimento Portland, para os traços 1:3,5 e 1:5,0. O material por ser orgânico, não o impede de ser aproveitado em argamassas, sendo que um elemento fibroso que apresenta um ótimo desempenho de resistência axial ( $\mathrm{MPa}$ ) para concretos. Tal referência se condiz aos exemplos de muitos pesquisados que tem aproveitado o material em pavimentações de calçadas e entre outros. Assim sendo, a fibra do coco pode ser um elemento chave na busca e melhora das condições degradáveis, assim recuperando e apresentando redução de custos da obra.

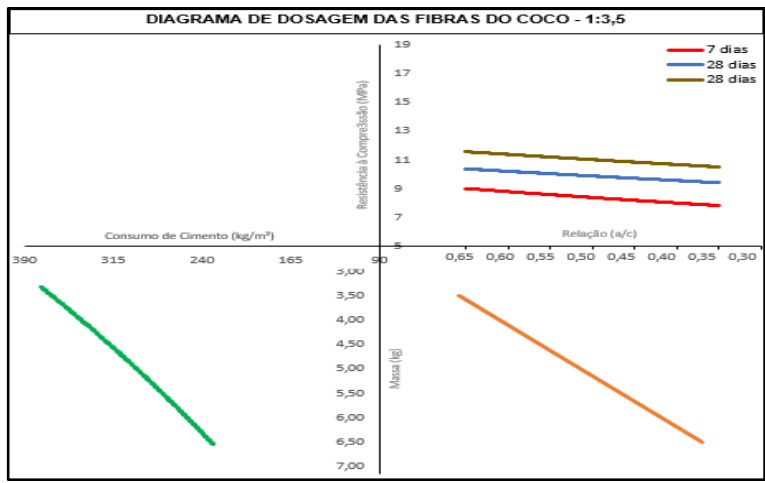

(a)

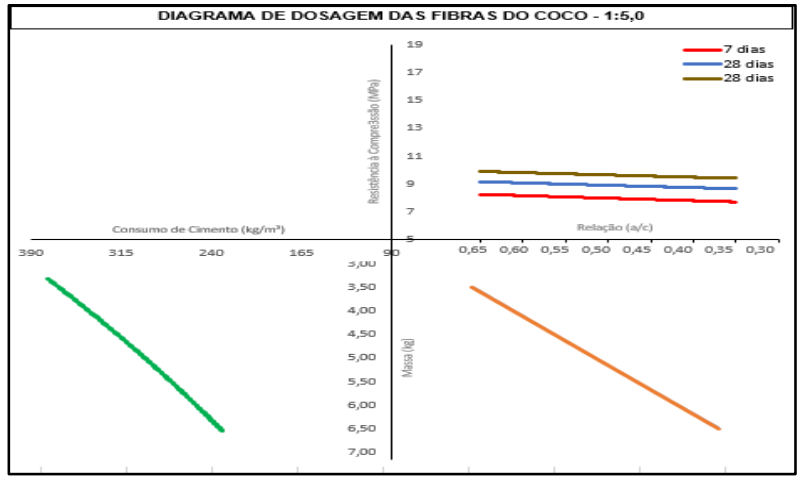

(b)

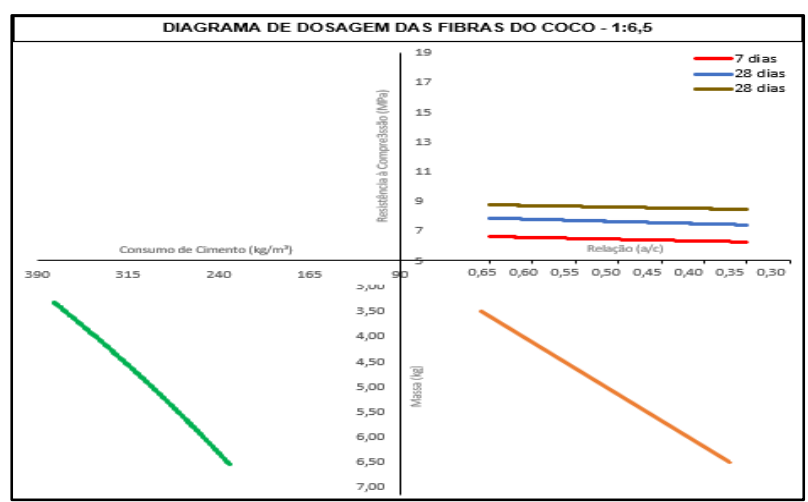

(c)

Figura 4: Apresentação das curvas de Abrams, Lyse e Molinari dos concretos com adição da fibra do coco (CAFC), segundos os traços: 1:3,5 (a); 1:5,0 (b) e 1:6,5 (c).

Para todas essas análises, é preciso destacar a importância em se reutilizar materiais que são descartados e não aproveitados em diversos pontos da sociedade.

\section{Conclusões}

Foi possível através deste, definir algumas características dos componentes da argamassa, sendo eles o cimento, agregado miúdo (areia) e agregado graúdo.

A granulometria dos agregados miúdos influência na dosagem do aglomerante hidraúlico e na quantidade de água, quando existe deficiência na curva granulométrica, ou seja, a curva não é continua, ou excesso de finos, ocorre um maior consumo de água, podendo reduzir as propriedades mecânicas e causar maior retração por secagem.

Quanto a granulometria, densidade e absorção das britas, também aceitas pela norma, obtiveram suas propriedades definidas para a melhoria significativa no concreto, quando têm sua quantidade estipulada na 
relação a:p:a/c, uma vez que, a brita quando adicionada na mistura além de dar volume ao concreto, garante resistência à abrasão, que é o desgaste na superfície.

Correlacionando os traços de concreto, com a sua diferença entre o convencional e com o aditivo da fibra, recolheu-se os resultados do ensaio de compressão, e aplicou-se os mesmo em tabelas do software para agilizar o cálculo da dosagem e seus diagramas.

É possível concluir que os frutos do ensaio de compressão axial são significativos e válidos, com maior resistência quando rompidos após os 28 dias de sua confecção, ou seja, quanto mais tempo imerso em água, maior será o Mpa quando submetido a força de compressão, potencializando o efeito do concreto.

No que se refere as discrepâncias de um traço para outro, é detectável que o traço médio (1:5) obtém resistência mais elevada quando comparado ao pobre $(1: 6,5)$ e menor quando observado em relação ao rico $(1: 3,5)$, agindo como esperando.

Conclui-se, portanto, que a inspeção dos experimentos ocasionou em um estudo propício para o meio da construção civil, gerando frutos onde pode-se correlacionar uma argamassa com ótima viscosidade, quando a mesma for acrescida da fibra vegetal. Foi notável os resultados positivos, gerando boa fluidez e trabalhabilidade, na qual era a intenção primordial do estudo do concreto com adição do coco, sendo portanto, recomendado a mistura em pequenas quantidades, a fim de evitar fissuras e abranger seu potencial de resistência a compressão, gerando economia no preparo da argamassa associada à reutilização de matérias orgânicas, garantindo eficácia na construção civil.

\section{Referências Bibliográficas}

ABNT NBR NM 30: Agregado miúdo - Determinação da absorção de água. Rio de Janeiro: ABNT, 2001.

ABNT NBR NM 52: Determinação da massa específica aparente e absorção de água de agregados miúdos. Rio de Janeiro: $A B N T, 2003$.

ABNT NBR NM 53: Agregado graúdo - Determinação de massa específica, massa específica aparente e absorção de água. Rio de Janeiro: ABNT, 2003.

ABNT NBR NM 67: Concreto - Determinação da consistência pelo abatimento do tronco de cone. Rio de Janeiro: ABNT, 1998.

ABNT NBR NM 248: Agregados - Determinação da composição granulométrica. Rio de Janeiro: ABNT, 2003. ABNT NBR NM 7211: Agregados para concretos - especificação. Rio de Janeiro: ABNT, 2009.

BOLOGNINI, E. J. et al. Determinação da dosagem de concreto. XII Congresso Iberoamericano de Engenharia Mecânica (CIBIM). Guayaquil: Equador, p.156-163, 2015.

HELENE, P.; TERZIAN, P. Manual de dosagem e controle do concreto. São Paulo: Pini, 1993. 349 p

OTIENO, M.; IKOTUN, J.; BALLIM, Y. Experimental investigations on the influence of cover depth and concrete quality on time to cover cracking due to carbonation-induced corrosion of steel in RC structures in an urban, inland environment. Construction and Building Materials, Vol. 198, 2019, p. 172 - 181, ISSN $0950-0618$. https://doi.org/10.1016/j.conbuildmat.2018.11.215

SILVA, E.; MARQUES, M.; JR FORNARI, C. Aplicação de fibra de coco em matrizes cimentícias. Rev. Elet. em Gestão, Educação e Tecnologia Ambiental, v(8), no 8, p. 1555-1561, SET-DEZ, 2012. http://dx.doi.org/10.5902/223611706096

YOUNIS, K. H.; PILAKOUTAS, K. Strength prediction model and methods for improving recycled aggregate concrete. Elsevier - Construction and Building Materials, Vol. 49, p. 688-701, 2013. 